\title{
PERAN KELEMBAGAAN PETERNAK DALAM ADOPSI TEKNOLOGI
}

\author{
${ }^{1}$ Anang Febri Prasetyo, ${ }^{2}$ Aan Awaludin \\ ${ }^{1}$ Program Studi Manajemen Bisnis Unggas, ${ }^{2}$ Program Studi Produksi Ternak Jurusan Peternakan \\ Politeknik Negeri Jember \\ Jalan Mastrip Kotak Pos 164 Jember \\ anang_fp@yahoo.com
}

\begin{abstract}
Selama ini kelembagaan peternak masih dipandang belum mampu menjadi sarana untuk meningkatkan adopsi teknologi dan sarana dalam bertukar informasi didalam kelompok peternak. Tujuan penelitia ini untuk menganalisis peranan kelembagaan peternak dalam meningkatkan adopsi teknologi. Penelitian ini dilakukan pada kelompok ternak lembahmeru, Kabupaten Jember dengan jumlah sampel seluruh anggota yang berjumlah sebanyak 20 peternak. Penelitian ini menggunakan pendekatan kuantitatif dengan analisis korelasi. Peran kelembagaan di kelompok ternak lembah meru terkait penyebaran informasi teknologi, wadah kerjasama, dan pendapatan peternak cukup tinggi. Namun, peran kelembagaan dalam edukasi peternak masih dirasakan belum optimal. Penerapan teknologi di kelompok ternak lembah meru masih sangat rendah. Hal ini kelompok ternak lembah meru sedang pada tahap menilai teknologi.berdasarkan hasil analisis korelasi antara peran kelembagaan dengan tingat adopsi teknologi peternak di kelompok ternak lembah meru tidak memiliki pengaruh, namun hasil analisi menunjukkan nilai yang positif. Diharapkan kepada kelompok ternak lembah meru mampu meningkatkan edukasi kepada anggota kelompok ternak dalam penerapan teknologi.
\end{abstract}

Kata kunci : Adopsi Teknologi, Kelompok Ternak, Peran Kelembagaan

\begin{abstract}
All this time institution breeder is still seen not to be a means to improve technology adoption and exchanging information on the livestock group. The purpose of this study to analyzing the role of livestock groups in improving technology adoption. The study was conducted on lembah meru livestock groups, Jember Regency with a population of 20 members. This study use kuantitatif approach with correlation analysis. Institutional role in lembah meru livestock groups in the spread of information technology, cooperation, income for breeder is still high. However, Institutional role to education for breeder is still not optimal. Application of technology in Lembah Meru livestock groups is still very low. In this case, Lembah Meru livestock groups are at the stage of assessing the technology. Based on the analysis of correlation between the institutional role with adoption technology Lembah Meru livestock groups has no influence. But the analysis results indicate a positive value. Be expected Lembah Meru livestock groups able to increase education for breeder in the application of technology.
\end{abstract}

Key Words : Adoption Technology, Livestock Groups, Role of Institutional

\section{PENDAHULUAN}

Kelembagaan peternak yang ada di Kabupaten Jember sebagian besar adalah komoditi ternak kambing dan domba. Banyak kelembagaan peternakan yang selama ini hanya terfokus dalam produksi ternaknya saja, sehingga kelembagan ternak tersebut lupa untuk melakukan adopsi teknologi. Menurut Hermanto dan Swastika (2011) kelompok dapat mememainkan peranan sebagai penyedia input usaha tani/ternak, penyedia modal, penyedia informasi, dan berperan dalam pemasaran secara kolektif. Padahal usaha peternakan adalah bagian dari usaha pertania yang tidak dapat dipisahkan, sehingga usaha peternakan dapat diintegrasikan dengan usaha pertanian, yaitu dengan cara mengadopsi teknologi untuk mengolah limbah peternakan menjadi pupuk organik yang dapat dimanfaatkan dalam usaha pertanian, begitu juga sebaliknya mengolah limbah pertanian menjadi pakan ternak. Teknologi sederhana ini umumnya sudah diketahui oleh 
sebagian besar peternak, namun untuk menyebarluaskannya diperlukan kelembagaan yang baik sehingga proses adopsi teknologi oleh anggota kelompok dapat berjalan dengan baik.

Kelembagaan peternakan diharapkan menjadi sarana untuk meningkatkan adopsi teknologi dan sarana dalam bertukar informasi diantara peternak. Pambudy (2006) menyebutkan beberapa kendala peningkatan peranan kelompok dalam mengembangkan usahannya, diantarannya : 1) pengetahuan dan manajemen anggota yang relatif rendah, 2) kurangnya jaminan terhadap ketersediaan faktor produksi, 3) kurangnya akses dan pengetahuan terhadap pasar, 4) kurangnya akses mendapatkan modal, serta kurangnya kesadaran anggota akan fungsi dan peran kelompok dalam pengembangan usaha, 5) kualitas produk yang dihasilkan oleh anggota masih rendah.Namun demikian selama ini kelembagaan peternak masih dipandang sebagai obyek untuk melaksanakan suatu hasil kepeutusan institusi yang lebih tinggi dengan perencanaan yang sentralistik "Top Down" yang mengakibatkan kelembagaan peternak menjadi lemah, ketergantungan, dan tidak berkembang. Akibanya kelembagaan peternak tidak mendorong anggotanya untuk melakukan melakukan kreativitas dalam mengembangkan ideide baru, dan kurang mendorong partisipasi anggotannya.Dari uraian latar belakang masalah diatas maka peneliti tertarik untuk meneliti tentang "peran kelembagaan peternak dalam meningkatkan adopsi teknologi pada kelompok ternak lembah meru".

Tujuan dan Manfaat Penelitian A. Tujuan Penelitian

Kajian ini bertujuan untuk menganalisis hubungan peran kelembagaan dalam meningkatkan adopsi teknologi di kelompok ternak lembah meru. B. Manfaat Penelitian

Diharapkan dengan adanya penelitian ini dapat diketahui hubungan peran kelembagaan dalam meningkatkan adopsi teknologi.

\section{METODOLOGI PENELITIAN}

$\begin{array}{lccr}\text { Penetapan } & \text { lokasi penelitian diambil } \\ \text { secara } & \text { sengaja } & \text { (purposive) } & \text { berdasarkan } \\ \text { pertimbangan- } & \text { pertimbangan } & \text { tertentu }\end{array}$ (Singarimbun dan Effendi, 1995) yaitu pada kelompok ternak lembah meru. Sampel yang digunakan adalah seluruh anggota kelompok yang berjumlah 20 peternak. Penelitian ini menggunakan metode diskriptif dengan strategi studi kasus. Nazir (2003) menjelaskan bahwa metode diskriptif adalah suatu metode dalam meneliti suatu kelompok. Penggambilan data dilakukan menggunakan kuesionare. Data yang diambil dalam penelitian ini dibagi menjadi 2 yaitu: 1) data primer yaitu data utama yang diambi menggunakan kuesionare dan FGD (Focus Group Discusion) dan, 2) data sekunder yaitu data pendukung yang didapat dari literatur maupun catatan kelompok. Data hasil penelitian ini didiskripsikan dan dianalisis menggunakan analisis korelasi dengan bantuan SPSS 17.

\section{HASIL dan PEMBAHASAN}

A. Peran Kelembagaan

Peran kelembagaan peternakan sangat penting ditujukan untuk kemandirian dan ketangguhan kelompok peternak untuk melakukan adopsi teknologi. Unsur yang dilihat dalam peran kelembagaan yaitu penyebaran teknologi dan informasi, wadah kerjasama, edukasi peternak, peningkatan pendapatan peternak. Hasil analisis dari masing-masing unsur dijelaskan seperti berikut:

1. Penyebaran Teknologi dan Informasi

Penyebaran teknologi dan informasi oleh kelembagaan peternakan sangat diperlukan untuk meningkatkan proses adopsi teknologi. Berdasarkan hasil penelitian penyebaran teknologi dan informasi didalam kelompok ternak nampak pada tabel 1 .

Berdasarkan pada tabel 1. sebanyak $75 \%$ anggota kelompok yang menyatakan melakukan penyebaran teknologi dan informasi. Sebanyak $85 \%$ anggota kelompok menyatakan menerapkan teknologi yang disampaikan dalam diskusi kelompok. Sebanyak 60\% anggota kelompok membuat inovasi dan diterapkan. Sedangkan sebanyak $70 \%$ anggota kelompok menyatakan bahwa kelembagaan kelompok berfungsi untuk pertukaran informasi. Hal ini sejalan dengan pendapat Suradisastra (2009) bahwa fungsi kelompok dapat meningkatkan akses petani ke sumber informasi.

Tabel 1. Penyebaran Teknologi dan Informasi

\begin{tabular}{lcccc}
\hline \multirow{2}{*}{ Keterangan } & \multicolumn{2}{c}{ Tinggi } & \multicolumn{2}{c}{ Rendah } \\
\cline { 2 - 5 } & $\mathrm{n}$ & $\%$ & $\mathrm{n}$ & $\%$ \\
\hline $\begin{array}{l}\text { Melakukan } \\
\begin{array}{l}\text { Menerapkan teknologi } \\
\text { yang disampaikan dalam }\end{array}\end{array}$ & 15 & 75 & 5 & 25 \\
$\begin{array}{l}\text { diskusi kelompok } \\
\begin{array}{l}\text { Membuat inovasi dan } \\
\text { diterapkan }\end{array}\end{array}$ & 3 & 15 \\
$\begin{array}{l}\text { Berfungsi untuk } \\
\text { pertukaran informasi }\end{array}$ & 12 & 60 & 8 & 40 \\
\hline
\end{tabular}

Sumber: Data primer olahan (2016) 
Sejalan dengan penelitian Teo et al. (2007) mengatakan bahwa secara garis besar inisiatif organisasi merupakan hal yang sangat diperlukan untuk mempercepat proses adopsi inovasi baru melalui penyebaran teknologi dan informasi. Berkaitan dengan peran kelembagaan dalam meningkatkan kapabilitas adopsi teknologi, Jane (2011) juga mengemukakan Model 3D, dimana agar perusahaan dapat meningkatkan kapabilitas inovasi dan teknologikalnya.

\section{Wadah kerjasama}

Kelembagaan peternakan amat penting perannya untuk menjadi wadah kerjasama diantar setiap anggota kelompok untuk mencapai tujuan. Berdasarkan hasil peelitian seluruh anggota kelompok menyatakan bahwa kelembagaan peternakan ini sudah menjadi wadah kerjasama bagi setiap anggota kelompoknya. Hal tersebut terlihat dalam tabel 2. Sebagai berikut.

Tabel 2. Wadah Kerjasama

\begin{tabular}{lcccc}
\hline \multirow{2}{*}{ Keterangan } & \multicolumn{2}{c}{ Tinggi } & \multicolumn{2}{c}{ Rendah } \\
\cline { 2 - 5 } & $\mathrm{n}$ & $\%$ & $\mathrm{n}$ & $\%$ \\
\hline Wadah Kerjasama & 20 & 100 & 0 & 0 \\
\hline
\end{tabular}

Sumber: Data primer olahan (2016)

\section{Edukasi peternak}

Dalam rangka meningkatkan pengetahuan dan kemampuan peternak maka edukasi peternak menjadi sangat penting. Peran kelembagaan dalam melakukan edukasi peternak nampak sudah terlihat seperti dalam tabel 3. Di dalam kelompok ternak ini, sebanyak $70 \%$ anggota kelompok menyatakan lembaga pernah mengikuti pelatihan teknis budidaya ternak. Sedangkan, hanya $45 \%$ anggota kelompok yang menyatakan pernah mengikuti pelatihan panen dan pasca panen. Dan sebanyak $65 \%$ anggota kelompok pernah mengikuti pelatihan teknologi peternakan. Sejalan dengan hasil penelitian ini Huysman dan Wit (2003) mengemukakan konsepknowledge sharingyaitu konsep berbagi informasi dan pengetahuan yang dapat diakselerasi melalui pengembangan kelembagaan petani peternak baik melalui pelatihan maupun pertukaran informasi.

$\underline{\text { Tabel 3. Edukasi Peternak }}$

\begin{tabular}{lcccc}
\hline \multirow{2}{*}{ Keterangan } & \multicolumn{3}{l}{ Tinggi } & \multicolumn{3}{c}{ Rendah } \\
\cline { 2 - 5 } & $\mathrm{n}$ & $\%$ & $\mathrm{n}$ & $\%$ \\
\hline $\begin{array}{l}\text { Pelatihan teknis budidaya } \\
\begin{array}{l}\text { Pelatihan panen dan pasca } \\
\text { panen }\end{array}\end{array}$ & 14 & 70 & 6 & 30 \\
$\begin{array}{l}\text { Pelatihan teknologi } \\
\text { peternakan }\end{array}$ & 9 & 45 & 11 & 55 \\
\hline
\end{tabular}

Sumber: Data primer olahan (2016)

4. Peningkatan Pendapatan Peternak

Peran kelembagaan dalam hal meningkatkan pendapatan peternakan sudah sangat baik. Hal ini seperti terlihat dalam tabel 4. yaitu dari sebanyak 95\% anggota kelompok menyatakan terdapat kenaikan produksi. Sebanyak $75 \%$ anggota kelompok menyatakan terdapat kenaikan pendapatan usaha dan sebanyak 90\% anggota kelompok menyatakan terdapat efisien biaya dan tenaga kerja.

Tabel 4. Peningkatan Pendapatan Peternak

\begin{tabular}{lcccc}
\hline \multirow{2}{*}{ Keterangan } & \multicolumn{2}{c}{ Tinggi } & \multicolumn{2}{c}{ Rendah } \\
\cline { 2 - 5 } & $\mathrm{n}$ & $\%$ & $\mathrm{n}$ & $\%$ \\
\hline Kenaikan produksi & 19 & 95 & 1 & 5 \\
Kenaikan pendapatan usaha & 15 & 75 & 5 & 25 \\
Efisiensi biaya dan tenaga kerja & 18 & 90 & 2 & 10 \\
\hline
\end{tabular}

Sumber: Data primer olahan (2016)

B. Tingkat adopsi teknologi peternak

Adopsi teknologi yang telah dilakukan oleh peternakan pada kelompok ternak lembah meru nampak sudah ada meskipun belum berlangsung dengan baik. Tingkat adopsi teknologi peternakan dilihat dari unsur kesadaran, minat, menilai, mencoba, dan menerapkan. Masing -masing unsur akan dijelaskan seperti pada tabel 5. Berikut ini:

Tabel 5. Tingkat adopsi teknologi peternakan

\begin{tabular}{lcccccc}
\hline \multirow{2}{*}{ Keterangan } & \multicolumn{2}{c}{ Tinggi } & \multicolumn{2}{c}{ Sedang } & \multicolumn{2}{c}{ Rendah } \\
\cline { 2 - 7 } & $\mathrm{n}$ & $\%$ & $\mathrm{n}$ & $\%$ & $\mathrm{n}$ & $\%$ \\
\hline Tahap Kesadar & 4 & 20 & 11 & 55 & 5 & 25 \\
Tahap Minat & 6 & 30 & 0 & 0 & 14 & 70 \\
Tahap Menilai & 13 & 65 & 2 & 10 & 5 & 25 \\
Tahap Mencoba & 7 & 35 & 0 & 0 & 13 & 65 \\
Tahap Menerapkan & 1 & 5 & 0 & 0 & 19 & 95 \\
\hline
\end{tabular}

Sumber: Data primer olahan (2016)

Kesadaran terhadap teknologi. Berdasarkan hasil survey hanya sebanyak $20 \%$ saja dari anggota kelompok yang memiliki kesadaran yang tinggi akan adopsi teknologi peternak. Mereka mencari tahu mengenai informasi teknologi yang telah diadopsi. Namun, sebesar 55\% anggota kelompok tergolong memliki kesadaran sedan karena hanya sekedar tertarik saja terhadap teknologi. Sedangkan sebanyak 25\% anggota kelompok memiliki kesadaran rendah pada adopsi teknologi.

Minat terhadap teknologi. Berdasarkan hasil survey menyatakan bahwa hanya 30\% anggota kelompok yang memiliki minat tinggi terhadap adopsi teknologi. Sedangkan 70\% anggota kelompok memiliki minat rendah terhadap hasil adopsi teknologi. 
Menilai teknologi. Berdasarkan hasil survey nampak bahwa kelompok ternak pada tinkatan menilai adopsi teknologi sudah cukup tinggi. Sebanyak 65\% anggota kelompok telah melakukan penilaian terhadap adopsi teknologi yang ada. Mereka telah melakukan perhitungan keuntungan dalam menggunakan teknologi yang ada.

Mencoba teknologi baru.Berdasarkan hasil survey nampak bahwa kelompok ternak sudah berusaha mencoba melaksanakan adopsi teknologi. Sebanyak $35 \%$ anggota kelompok sudah mencoba teknologi dengan baik. Dan sebanyak $65 \%$ anggota kelompok mencoba teknologi pada skala yang lebih kecil terlebih dahulu.

Menerapkan teknologi. Berdasarkan hasil survey nampak bahwa kelompok ternak masih tergolong rendah dalam menerapkan adopsi teknologi usaha peternakan. Hanya sebanyak 5\% saja dari anggota kelompok ternak yang senantiasa berusaha mengadopsi dan mencari inovasi teknologi guna menunjang keberhasilan kelompok untuk mencapai hasil yang maksimal.

\section{Hubungan peranan kelompok dalam adopsi teknologi}

Hasil analisis korelasi antara peran kelembagaan dengan tingkat adopsi teknologi menunjukkan nilai koefisen $=0,198$ yang artinya nilai tersebut $>\alpha=0,05$ (taraf signifikan 5\%). Hal ini menunjukkan bahwa peran kelembagaan tidak berkorelasi signifikan terhadap adopsi teknologi. Hai ini dapat dijelaskan berdasarkan tabel 6 . seperti dibawah ini.

Tabel 6. Hasil analisis Korelasi

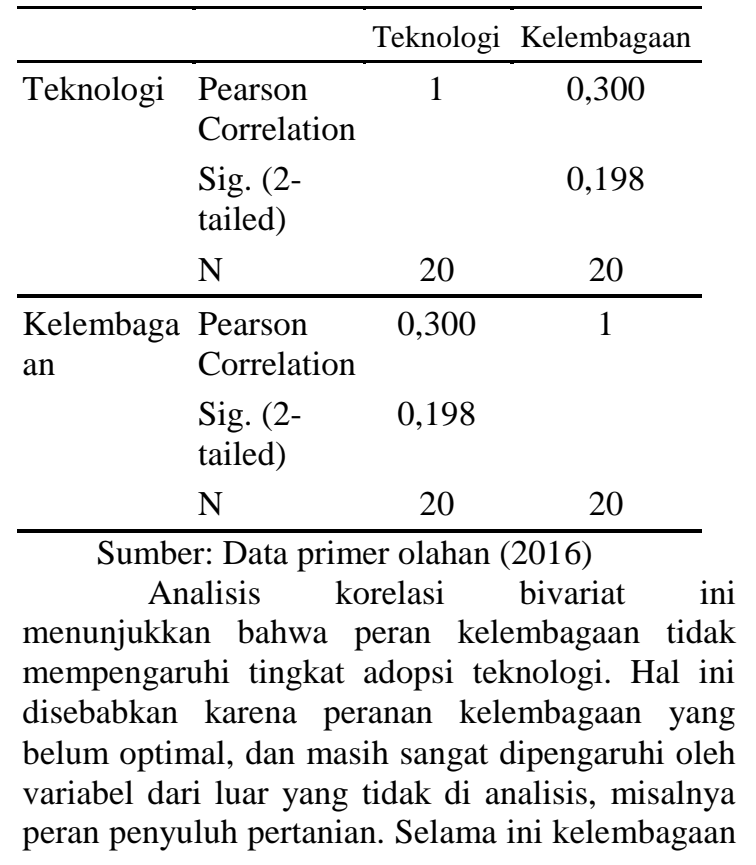

peternak belum dapat berjalan secara optimal, dan lebih banyak merupakan bagian dari program pemerintah yang digerakkan secara top down. Hal ini terbukti dari hasil FGD, bahwa kelompok lembah meru sering mendapatkan program pemerintah.

\section{KESIMPULAN dan SARAN}

A. Kesimpulan

Peran kelembagaan dalam adopsi teknologi dinilai sangat penting. Peran kelembagaan di kelompok ternak lembah meru terkait penyebaran informasi teknologi, wadah kerjasama, dan pendapatan peternak cukup tinggi. Namun, peran kelembagaan dalam edukasi peternak masih dirasakan belum optimal. Penerapan teknologi di kelompok ternak lembah meru masih sangat rendah. Hal ini kelompok ternak lembah meru sedang pada tahap menilai teknologiberdasarkan hasil analisis korelasi antara peran kelembagaan dengan tingat adopsi teknologi peternak di kelompok ternak lembah meru tidak memiliki pengaruh, namun hasil analisi menunjukkan nilai yang positif.

\section{B. Saran}

Diharapkan kepada kelompok ternak lembah meru mampu meningkatkan edukasi kepada anggota kelompok ternak dalam penerapan teknologi.

\section{DAFTAR PUSTAKA}

Hermanto, K. S \& D. Swastika. 2011. Penguatan kelompok tani : langkah awal peningkatan $\mathrm{k}$ esejahtraan petani. Jurnal Analisis Kebijakan Pertanian. Vol. 9 : 371-390.

Huysman, M and Wit D. 2003. A Critical Evaluation of Knowledge Management Practices. Sharing Expertise-Beyond Knowledge Management. MIT press.

Jane O. 2011. Analisis Potensi Partnership sebagai Modal untuk Meningkatkan Kapabilitas Inovasi dan Teknologi. Jurnal Administrasi Bisnis (2011). 7(2):192-205. Center for Business Studies. FISIP-Unpar.

Nazir, M. 2003. Metodologi Penelitian. Ghalia Indonesia, Jakarta.

Pambudy, R. 2006. Ketahanan pangan dalam sistem dan usaha agribisnis : pemberdayaan petani dan organisasi petani. Prosiding Seminar Hasil Pangan Sedunia XXVI ; Jakarta, 13 September 2006.

Suradisastra. 2008. Strategi Pemberdayaan Kelembagaan Petani. Pusat Analisis Sosial Ekonomi dan Kebijakan Pertanian. Forum Penelitian Agro Ekonomi. 26(2):82-91. Desember 2008 
Jurnal Ilmiah INOVASI, Vol. 1 No. 2 Edisi Mei-Agustus 2016, ISSN 1411-5549

Singarimbun dan Effendi . 1995. Metode Penelitian Survei. LP3ES. Jakarta

Teo TSH, Lim GS, and Fedric SA. 2007. The Adoption and Diffusion of Human Resources Information Systems in Singapore. Asia Pacific Journal of Human Resources. 45(1):44-62 